\title{
HUBUNGAN STATUS PEKERJAAN IBU DENGAN PENCAPAIAN PERKEMBANGAN MOTORIK PADA ANAK USIA 5-7 TAHUN
}

\author{
Lia Kurniasari*, Shella Karina* \\ Email : liakesmas@umkt.ac.id
}

\begin{abstract}
ABSTRAK
Periode sejak janin dalam kandungan sampai anak berusia 6 tahun merupakan periode yang sangat penting dalam pertumbuhan dan perkembangan yang paling pesat pada otak manusia. Salah satu perkembangan anak yang penting untuk dipantau pada periode ini adalah perkembangan motorik. Peran orang tua dalam perkembangan motorik sangat diperlukan terutama seorang ibu. Ibu yang seharusnya memberikan stimulasi dalam tumbuh kembang anak harus bekerja membantu ayah mencari nafkah, sehingga waktu tumbuh kembang anak tidak bisa dipantau oleh orang tua. Penelitian ini bertujuan untuk melihat apakah ada hubungan status perkerjaan ibu dengan pencapaian perkembangan motorik pada anak usia 5-7 tahun. Metode penelitian ini kuantitatif dengan cross sectional. Sampel penelitian ini berjumlah 130 responden. Analisis hubungan antara Status Pekerjaan Ibu dengan Pencapian Perkembangan Motorik Anak menggunakan rumus Person chi-Square dengan taraf signifikan a $5 \%$ dengan nilai $P$ Value $0.371>$ a 0,05 yang berarti tidak ada hubungan Status Pekerjaan Ibu dengan Pencapaian Perkembangan Motorik Anak Usia 5-7 Tahun. Kualitas dalam pengasuhan anak menjadi hal yang paling diperlukan untuk setiap orang tua. Komunikasi dengan pihak lain yang terlibat seperti guru di sekolah menjadi salah satu upaya untuk memantau perkembangan anak di sekolah.
\end{abstract}

Kata Kunci : Status Pekerjaan Ibu, Perkembangan Motorik Anak

\section{ABSTRACT}

Period since fetus in the womb to children age of 6 years old was very important period in rapid growth and development on humans brain. One of the important childrens development to be observed on this period was motor development. Parents role in motor development were very needed especially mother's role. Mother who should give stimulation in children growth and development must went to work to help father earning money, then children's growth and development period could not be observed by the parents. This research aimed to observe if there were correlation between mothers job status and motor development achievement on children age of 5-7 years old. This research method was quantitative with cross-sectional. These research samples total were 130 respondents. Correlation analysis between Mothers Job Status with Children's Motor Development used Pearson Chi-Square with margin of error a $5 \%$ with p-value $0.371>$ a 0,05 which meant there were no correlation between Mothers Job Status and Children's Motor Development Achievement age of 5-7 years old. Quality in children caring became indispensible for every parent. Communication with other related parties such as teacher in school became one of effort to observe children's development in school.

Keywords: Mothers Job Status, Children's Motor Development

\section{PENDAHULUAN}

Tahun pertama kehidupan, terutama periode sejak janin dalam kandungan sampai anak berusia 6 tahun, periode ini sangat penting dalam pertumbuhan dan perkembangan yang paling pesat pada otak manusia. Perkembangan adalah bertambahnya kemampuan fungsi semua sistem organ tubuh akibat bertambahnya kematangan

*. Universitas Muhammadiyah Kalimantan Timur 
fungsi sistem organ tubuh, bersifat reversible serta kuantitatif meliputi: kemampuan gerak kasar dan halus, pendengaran, penglihatan, komunikasi, bicara, emosi-sosial, kemandirian, intelegensi, dan perkembangan moral( $L$, 2014). Salah satu perkembangan anak yang penting untuk dipantau pada periode ini adalah perkembangan motorik karena perkembangan motorik merupakan perkembangan gerakan jasmaniah melalui kegiatan pusat syaraf, urat syaraf, dan otak yang terkoordinasi(Hurlock, 1997). Perkembangan motorik terbagi menjadi dua motorik kasar dan halus. Motorik kasar adalah gerakan tubuh yang menggunakan otot-otot besar sebagai dasar utama dalam gerakannya meliputi perkembangan gerakan kepala, badan, anggota badan, keseimbangan dan pergerakan, contohnya seperti meloncat dan berlari. Motorik halus adalah kemampan gerakan yang dilakukan otototot halus, tidak memerlukan tenaga tetapi membuthkan koordinasi tangan dan mata yang cermat, contohnya seperti mewarnai dan meronce(Soetjiningsih, 2013).

Menurut data yang didapatkan dari WHO 5-25\% anak usia prasekolah mengalami disfungsi otak minor, salah satunya gangguan perkembangan motorik halus.Menurut UNICEF tahun 2011, didapatkan data masih tingginya angka kejadian gangguan pertumbuhan dan perkembangan pada anak usia balita khususnya gangguan perkembangan motorik didapatkan $(27,55 \%)$ atau 3 juta anak mengalami gangguan perkembangan (UNICEF., 2011). Dari 200 juta anak di bawah usia 5 tahun di negara-negara berkembang, lebih dari sepertiganya tidak terpenuhi potensinya untuk perkembangan anak. Tidak terpenuhinya potensi perkembangan anak diperkirakan akan menyebabkan penghasilan anak tersebut di usia dewasa berkurang sebanyak $20 \%$ sehingga akan berimplikasi pada perkembangan nasional suatu bangsa(Kemenkes RI., 2014).

Berdasarkan hasil deteksi dini tumbuh kembang di Kota Samarinda Tahun 2016 sebesar 20\%. Pada tahun 2017 hasil deteksi dini tumbuh kembang di Kota Samarinda sebesar 23\%. Jika dibandingkan dengan indikator standar pelayanan minimal (SPM) bidang kesehatan kabupaten/kota sebesar 90\%, maka program SDIDTK Kota Samarinda masih sangat rendah(Wiwin Wayan $\mathrm{Ni}$, 2017). Berdasarkan data dari Dinas Kesehatan Kota tahun 2016 terdapat jumlah keseluruhan anak berusia 0 sampai dengan 7 tahun di wilayah Puskesmas Air Putih adalah 5.184 anak, dan pada tahun 2017 jumlah anak yang berusia 0 sampai dengan 7 tahun sebanyak 5.226 anak(Kota, n.d.).

Melihat dari data yang sudah dipaparkan, terdapat gangguan perkembangan pada anak, maka dari itu alasan yang cukup menjadi pertimbangan, yaitu perkembangan anak sangatlah penting di perhatikan bagi orang tua. Jika potensi perkembangan anak tidak terpenuhi akan menyebabkan ganggan pada perkembangan anak nanti di usia dewasa

Anak perlu mendapat stimulasi perkembangan sedini mungkin. Stimulasi tersebut merupakan kegiatan merangsang kemampuan dasar anak agar tumbuh dan berkembang secara optimal. Kurangnya stimulasi dapat menyebabkan penyimpangan tumbuh kembang anak bahkan gangguan yang menetap. Hal tersebut menuntut peran ibu sebagai orang tua untuk merawat dan melindungi anak guna mencapai pertumbuhan dan perkembangan yang optimal. Orang tua baik ayah maupun ibu yang sama-sama bekerja menyebabkan interaksi anatara orang tua dengan anak menjadi berkurang(Departemen Kesehatan RI, 2010).

Keluarga merupakan suatu sistem kompleks yang di dalamnya terdapat ikatan di antara anggotanya dan rasa saling memiliki. Di lingkungan keluarga inilah terjadi proses pengasuhan demi terbentuknya pribadi yang matang untuk dapat menjalani kehidupan sesuai yang diharapkan. Salah satu sosok yang paling berperan dalam pembentukan kepribadian tersebut adalah orang tua. Orang tua menjadi pendamping utama dalam setiap perkembangan anak-anak mereka. Orang tua menjadi contoh pertama dan yang paling utama bagi anak. 
Peran orang tua sangatlah
penting
dalam meningkatkan perkembangan anak, namun kenyataanya masih sering ditemukan kurangnya perhatian dari orang tua. Salah satunya karena sebagian orang tua terutama ibu harus membantu ayah dalam mencari nafkah untuk memenuhi ekonomi keluarga dan biasanya peran seorang ibu sering digantikan oleh orang dewasa lainnya seperti pengasuh bayi atau nenek ketika ibu sedang pergi bekerja. Ada sekian banyak alasan mengapa ibu bekerja, mulai dari memenuhi kebutuhan ekonomi keluarga sampai sebagai suatu bentuk aktualisasi diri. Pro dan kontra fenomena ibu bekerja.Ada pihak yang mengatakan ibu sebaiknya di rumah agar perkembangan anak lebih baik, tetapi ada yang berpendapat bahwa dengan diam di rumah belum menjamin perkembangan anak menjadi lebih baik.

Berdasarkan penelitian yang dilakukan oleh Imaniah, M. D. pada tahun 2013 bahwa perkembangan anak pada ibu yang tiak bekerja jauh lebih baik daripada ibu yang bekerja. Pada ibu yang tidak bekerja seluruh anak diketahui memiliki perkembangan bahasa, motorik, kognitif dan sosial. Sedangkan, pada ibu yang bekerja sebagian perkembangan anaknya normal sebagiannya lagi perkembangannya kurang optimal dalam hal perkembangan bahasa dan sosial. Semua ini disebabkan karena sang ibu lebih banyak menghabiskan waktu ditempat kerja daripada bersama dengan anakanaknya. Sehingga perhatian sang ibu terhadap anak-anaknya juga berkurang(Imaniah, 2013).

Penelitian ini bertujuan untuk melihat apakah ada hubungan status perkerjaan ibu dengan pencapaian perkembangan motorik pada anak usia 5-7 tahun di wilayah puskesmas Air putih kota Samarinda.

\section{METODE PENELITIAN}

Metode yang digunakan adalah kuantitatif dengan pendekatan crosssectional studies. Variabel independen dalam penelitian ini adalah status pekerjaan ibu dan variabel dependen adalah perkembangan motorik anak. Sampel berjumlah 130 responden.
Sampel dipilih menggunakan Purposive Sampling menggunakan kriteria inklusi dan eksklusi. Kriteria inklusi dalam penelitian ini adalah Ibu atau anak yang bersedia berpartisipasi menjadi responden penelitian, Ibu yang memiliki anak usia 5 sampai 7 tahun, dan Ibu yang anaknya terdaftar di Taman KanakKanak (TK) di wilayah kerja puskesmas Air Putih yaitu Taman Kanak-Kanak Melati Putih Plus, Taman Kanak-Kanak Aisyiyah Bustanul Athfal (ABA 3) dan Taman Kanak-Kanak (TK) Al Hidayah. Kriteria eksklusi dalam penelitian ini adalah Mengundurkan diri sebagai subyek penelitian dan Tidak berada ditempat pada waktu penelitian. Definisi oprasional variabel independen yaitu Status Pekerjaan Ibu, Ibu yang bekerja merupakan ibu yang bekerja diluar rumah lebih dari 6 jam yang terhubung dengan kontrak untuk mendapatkan pengahasilan disamping membesarkan dan menguurus anak dirumah. Sedangkan Ibu yang tidak bekerja adalah ibu yang tidak menjalankan karir profesional, melainkan hanya menjalankan tugas ibu rumah tangga.Variabel dependen Perkembangan Motorik Anak Kemampuan perkembangan motorik anak dilihat dari motorik kasar dan motorik halus pada anak usia 5-7 tahun. Instrument penelitian yang digunakan adalah survei dengan kuesioner dan observasi. Lembar kuesioner dibagikan kepada orang tua murid yang bersekolah di Taman Kanak-Kanak (TK) dan lembar observasi responden diisi dan dinilai oleh peneliti secara langsung Analisa data menggunakan Chi square dengan nilai a $5 \%$ dengan bantuan software statistic spss.

\section{HASIL}

\section{Analisis Univariat}

Berdasarkan tabel 1 dibawah menggunakan rumus Sturges dengan 36 jarak atau rentangan data, 6 kelas interval dan 6 panjang kelas interval. Dapat diperoleh informasi bahwa usia responden orang tua terbanyak pada usia 31-37 tahun sebanyak 57 orang (43.8\%). Berdasarkan table dibawah diperoleh informasi bahwa mayoritas pekerjaan orang tua adalah Informal sebanyak 109 orang (83.8\%). Pekerjaan 
informal merupakan pekerjaan yang mengandalkan fisik, dan membuka lapangan usaha di sektor pertanian dan lain-lainnya. Pekerjaan informal seperti ibu rumah tangga, pedagang dan wiraswasta. Berdasarkan tabel dibawah diperoleh informasi bahwa usia responden anak terbanyak pada usia 7 Tahun sebanyak 65 orang (50.0\%). Berdasarkan tabel dibawah diperoleh informasi bahwa mayoritas Status Pekerjaan Ibu adalah Ibu yang tidak bekerja sebanyak 83 orang (63.8\%). Berdasarkan tabel dibawah diperoleh data median karena data bersifat tidak normal dan sudah di uji normality dengan menggunakian spss. diperoleh informasi bahwa mayoritas Perkembangan Motorik adalah Tidak Tercapai sebanyak 69 orang (53.1\%).
Tabel 1

Hasil Univariat Distribusi Frekuensi Responden

\begin{tabular}{lcc}
\hline \multicolumn{1}{c}{ Variabel } & Frekuensi & Presentase \\
\hline Usia & 10 & $7.7 \%$ \\
17-23 Tahun & 40 & $30.8 \%$ \\
$24-30$ Tahun & 57 & $43.8 \%$ \\
$31-37$ Tahun & 15 & $11.5 \%$ \\
$38-44$ Tahun & 3 & $2.3 \%$ \\
45-51 Tahun & 5 & $3.8 \%$ \\
52-58 Tahun & & \\
Pekerjaan & 109 & $83.8 \%$ \\
Informal & 21 & $16.2 \%$ \\
Formal & & \\
Usia Anak & 16 & $12.3 \%$ \\
5 Tahun & 49 & $37.7 \%$ \\
6 Tahun & 65 & $50.0 \%$ \\
7 Tahun & & \\
Status Pekerjaan & \\
Ibu Tidak & & $63.8 \%$ \\
Bekerja & 83 & $36.2 \%$ \\
Ibu Bekerja & 47 & \\
Perkembangan & Motorik & $53.1 \%$ \\
Tidak Tercapai & 69 & $46.9 \%$ \\
Tercapai & 61 & \\
\hline n=130 & &
\end{tabular}

\section{Analisis Bivariat}

Tabel 2

Hasil Bivariat Status Pekerjaan Ibu dengan Perkembangan Motorik Anak

\begin{tabular}{|c|c|c|c|c|c|c|c|c|}
\hline \multirow{3}{*}{$\begin{array}{c}\text { Status } \\
\text { Pekerjaan } \\
\text { Ibu }\end{array}$} & \multicolumn{4}{|c|}{ Perkembangan Motorik } & \multirow{3}{*}{ Total } & \multirow{3}{*}{$\%$} & \multirow{3}{*}{$\begin{array}{c}\text { P } \\
\text { Value }\end{array}$} & \multirow{3}{*}{ OR } \\
\hline & \multicolumn{2}{|c|}{ Tidak Tercapai } & \multicolumn{2}{|c|}{ Tercapai } & & & & \\
\hline & $\mathbf{N}$ & $\%$ & $\mathbf{N}$ & $\%$ & & & & \\
\hline \multirow{2}{*}{$\begin{array}{c}\text { Ibu Bekerja } \\
\text { Ibu Tidak } \\
\text { Bekerja }\end{array}$} & 22 & $46.8 \%$ & 25 & $53.2 \%$ & 47 & 100.0 & \multirow[t]{2}{*}{0.371} & \multirow[t]{2}{*}{0.674} \\
\hline & 47 & $56.6 \%$ & 36 & $43.4 \%$ & 83 & 100.0 & & \\
\hline
\end{tabular}
$n=130$

Berdasarkan tabel 6 diatas diketahui bahwa dari 83 orang yang Status Pekerjaan Ibu tidak bekerja dengan Tidak Tercapai Perkembangan Motorik anak sebanyak 47 orang (56.6\%), dan Perkembangan Motorik Tercapai sebanyak 36 orang (43.3\%). Dari Status Pekerjaan Ibu Yang Bekerja dengan Tercapai Perkembangan Motorik anak sebanyak 25 orang (53.2\%), dan Ibu Bekerja yang Tidak Tercapai Perkembangan Motorik sebanyak 22 orang $(46.8 \%)$. Analisis hubungan antara Status Pekerjaan Ibu dengan Pencapian Perkembangan Motorik Anak menggunakan rumus Person chi-Square dengan taraf signifikan a $5 \%$ dengan nilai $P$ Value $0.371>$ a 0,05 sehingga $\mathrm{H}_{0}$ ditolak yang berarti tidak ada hubungan Status Pekerjaan Ibu dengan Pencapaian Perkembangan Motorik Anak Usia 5-7 Tahun, dengan nilai OR 0.674 yang artinya nilai OR 6 kali berpeluang Ibu yang Bekerja dengan perkembangan motorik tercapai.

\section{PEMBAHASAN}

\section{Analisis Univariat Status Pekerjaan} Ibu

Berdasarkan data yang diperoleh diatas mayoritas Status Pekerjaan Ibu adalah Ibu yang tidak bekerja sebanyak 83 orang $(63.8 \%)$ dan Ibu yang bekerja sebanyak 47 orang (36.2\%). Ibu yang bekerja merupakan ibu yang bekerja diluar rumah lebih dari 6 jam yang terhubung dengan kontrak untuk mendapatkan pengahasilan disamping 
membesarkan dan menguurus anak dirumah, sedangkan Ibu yang tidak bekerja adalah ibu yang tidak menjalankan karir profesional, melainkan hanya menjalankan tugas ibu rumah tangga.

Pengaruh orang tua yang bekerja umumnya berpengaruh terhadap pembentukan kepribadian anak, sikap, kebiasaan dan pola perilaku. Berdasarkan hasil penelitian yang dilakukan bahwa pekerjaan ibu paling banyak adalah Ibu Rumah Tangga (IRT) sebanyak $60 \%$ dan pekerjaan yang paling sedikit adalah PNS yaitu 16.7\%(Laloan et al., 2018).

Menurut asumsi peneliti dampak positif dari ibu yang bekerja akan lebih sering bertemu banyak orang, sehingga akan mendapatkan informasi yang lebih banyak dan pengetahuan akan bertambah. Bekerja yang dikembangkan akan memberikan pengetahuan dan keterampilan profesional serta pengalaman belajar selama bekerja.. Sebaliknya jika mayoritas Ibu Rumah Tangga (IRT) memiliki waktu lebih banyak di dalam rumah dan waktu yang dihabiskan bersama anak mereka juga akan lebih banyak.

\section{Analisis Univariat Perkembangan Motorik}

Berdasarkan data yang diperoleh diatas bahwa mayoritas Perkembangan Motorik adalah Tercapai sebanyak 61 orang (46.9\%) dan Tidak Tercapai sebanyak 69 orang (53.1\%). Dari perkembangan motorik yang penulis teliti, perkembangan anak banyak yang tidak tercapai pada ibu yang tidak bekerja sebanyak 38 orang $(69.1 \%)$ dan ibu bekerja sebanyak 17 orang (30.9\%).

Pada penelitian Hijja Cut Vina. W dan Suryane Sulistiana $S$ mengatakan bahwa peran orang tua khususnya ibu terhadap perkembangan anak-anaknya sangat penting terutama pada saat mereka berada pada usia balita, karena pada masa ini anak sudah mulai mengembangkan kemampuan dasar yang dimilikinya. Interaksi antara anak dan orang tua itu sangatlah bermanfaat bagi proses perkembangan anak secara keseluruhan. Orang tua khususnya ibu dapat segera mengenali kelainan dari proses perkembangan anaknya sedini mungkin dan memberikan stimulasi pada tumbuh kembang anak yang menyeluruh dalam keempat aspek yaitu motorik halus , motorik kasar, bahasa dan sosialisasi kemandirian. Peran ibu pada perkembangan anak sangat di perlukan untuk membantu anak dalam mencapai tumbuh kembang yang optimal(Hijja Cut Vina. W dan Suryane Sulistiana. S, 2018).

Menurut asumsi penelitian tercapainya atau tidak tercapainya perkembangan motorik anak pada ibu yang tidak bekerja tergantung bagaimana ibu memanfaatkan waktu dan perhatian bahkan untuk memberikan stimlasi khususnya pada perkembangan motorik untuk anaknya. Jika dilihat dari hal negatif pada ibu yang tidak bekerja waktu bersama anaknya tidak dapat dimanfaatkan secara optimal. Hal ini dikarenakan kebanyakan waktu yang mereka miliki digunakan untuk mengurusi domestik rumah tangga. Namun, jika ibu yang tidak bekerja mempunyai waktu yang lebih sering dan lebih banyak dalam melakukan stimulasi perkembangan khusunya perkembangan motorik anak. Selain itu ibu yang tidak bekerja juga diharapkan mampu mengatur pola makanan yang sehat dan bergizi untuk anaknya. Sehingga perkembangan anak akan lebih baik jika di bandingkan dengan ibu yang bekerja.

\section{Analisis Bivariat Hubungan Status Pekerjaan Ibu dengan Pencapaian Perkembangan Motorik Anak}

Perkembangan motorik

merupakan suatu proses kematangan atau gerakan yang langsung melibatkan otot-otot dan saraf untuk menggerakan anggota tubuh. Dari 130 responden anak, terdapat 69 responden (53.1\%) yang perkembangan motorik termasuk pada kategori tidak tercapai, dan 61 responden $(46.9 \%)$ pada kategori tercapai.

Dalam penelitian ini lebih dibahas terkait status pekerjaan ibu terkait pencapaian perkembangan motorik anak, dari hasil perhitungan menunjukan tidak ada hubungan antara status pekerjaan ibu dengan pencapaian perkembangan motorik anak. 
Hasil penelitian ini serupa dengan yang dilakukan oleh Christine Mariana Taju ,Yudi Ismanto dan Abram Babakal (2015) yang menggnakan uji Chi Square, dimana hasil penelitian menyatakan tidak terdapat hubungan antara status pekerjaan ibu dengan perkembangan motorik halus dan motorik kasar. Hasil analisis status pekerjaan ibu dengan perkembangan motorik halus diperoleh nilai signifikan $p=1,000$, dan dengan perkembangan motorik kasar $p=0,634$, maka dapat disimpulkan bahwa tidak terdapat hubungan antara status pekerjaan ibu dengan perkembangan motorik halus dan motorik kasar anak usia prasekolah $(p>0,05)$ (Taju et al., 2015).

$$
\text { Faktor-faktor yang dapat }
$$

mempengaruhi perkembangan anak adalah faktor lingkungan. Hal-hal yang yang termasuk pada faktor lingkungan diantaranya nutrisi dan stimulasi(Soetjiningsih \& Ranuh, 2014).Menurut asumsi peneliti bahwa perkembangan motorik anak bisa dilatih dengan memberikan stimulasi yang terarah dan teratur sehingga perkembangan motorik anak berkembang lebih cepat dan dengan memberikan asupan nutrisi yang baik akan mempengaruhi perkembangan anak. Asupan nutrisi akan berdampak pada status gizi anak yang mempengaruhi tumbuh kembangnya.

Fakta yang ada dilapangan saat penelitian berlangsung banyak orang tua yang jarang membuatkan bekal atau kotak nasi yang akan dibawa anak ke sekolah dan orang tua sering memberikan bekal ata kotak nasi tersebut digantikan dengan jajanan diluar seperti snack dan makanan capat saji yang kurang bergizi.

\section{SIMPULAN}

Karakteristik responden orang tua paling banyak responden berusia 31-37 tahun sebanyak 57 orang $(43.8 \%)$. Karakteristik responden orang tua Mayoritas pekerjaan orang tua adalah Informal sebanyak 109 orang (83.8\%). Karakteristik responden anak paling banyak berusia 7 Tahun sebanyak 65 orang (50.0\%). Dalam perhitungan hubungan didapatkan tidak adanya hubungan antara status pekerjaan ibu dengan pencapaian perkembangan motorik anak dengan taraf signifikan a $5 \%$ dengan nilai $\mathrm{P}$ Value $0.371>a$ 0,05 . Hal ini mengartikan tidak ada hubungan antara status pekerjaan ibu dengan pencapaian perkembangan motorik anak.

\section{SARAN}

Berdasarkan hasil penelitian ini dapat dibuat sebuah saran yaitu untuk sekolah yang berada di wilayah kerja puskesmas Air Putih, hendaknya membuat buku penghubung anak untuk orang tua. Buku penghubung ini berisikan tentang perkembangan anak di sekolah agar para orang tua bisa mengetahui perkembangan anaknya. Meskipun para borang tua sibuk dengan pekerjaan rumah tangga dan lain-lainnya ,para orang tua bisa memantau perkembangan anaknya lewat buku penghubung tersebut. Dan untuk para orang tua harus meningkatkan pengetahuan terkait perkembangan anaknya dengan cara mencai tahu informasi-informasi di sosial media, buku maupun seminar-seminar yang menyangkut perkembangan pada motorik anak.

\section{DAFTAR PUSTAKA}

Departemen Kesehatan RI, 2010. Depkes RI, Pedoman Pelaksanaan Stimulasi, Deteksi dan Intervensi DiniTumbuh Kembang Anak Di Tingkat Pelayanan Kesehatan Dasar, Jakarta.

Hijja Cut Vina. W dan Suryane Sulistiana. S, 2018. Perkembangan Anak Usia Pra Sekolah (3-5 tahun) dengan Ibu Yang Bekerja dan Ibu Yang Tidak Bekerja. Keperawatan (e-Kp) 4.

Hurlock, E.B., 1997. Hurlock, E.B. (1997). Perkembangan anak (child development) jilid 2. Diterjemahkan oleh Tjandrasa, M.M. Jakarta: PT. Erlangga.

Imaniah, M.D., 2013. Perbedaan Pencapaian Tugas Perkembangan Usia Anak Prasekolah Pada Ibu Yang Bekerja dan Ibu Yang Tidak Bekerja di Desa Serut Kecamatan Panti Kabupaten Jember. Keperawatan (e-Kp).

Kemenkes RI., 2014. Kemenkes RI, 
Profil Kesehatan Indonesia. Kemenkes RI: Jakarta.

Kota, D.K., n.d. Profil Dinas Kesehatan Kota Samarinda.

L, S., 2014. Saputra, L. Pengantar asuhan neonatus, bayi, dan balita. Bina Putra Aksara Publiser: Tangerang Selatan.

Laloan, M.M., Ismanto, A.Y., Bataha, Y., 2018. Perbedaan Perkembangan Anak Usia Toddler (1-3 Tahun) Antara Ibu Bekerja Dan Tidak Bekerja Di Wilayah Kerja Posyandu Puskesmas Kawangkoan. Keperawatan (eKp) 6.

Soetjiningsih \& Ranuh, I.N., 2014. Soetjiningsih \& Ranuh, I. N. Tumbuh Kembang Anak Edisi 2. Jakarta: Penerbit Buku Kedokteran EGC.

Soetjiningsih, R.G., 2013. Soetjiningsih, Ranuh G. Tumbuh kembang anak. Edisi ke-2. Denpasar: Penerbit Buku Kedokteran EGC.
Taju, C.M., Ismanto, A.Y., Babakal, A., 2015. Hubungan Status Pekerjaan Ibu Dengan Perkembangan Motorik Halus Dan Motorik Kasar Anak Usia Prasekolah Di Paud Gmim Bukit Hermon Dan Tk Idhata Kecamatan Malalayang Kota Manado. Keperawatan (e$\mathrm{Kp}) 2$.

UNICEF., 2011. UNICEF. Programming Experiences in Early Child Development. New York: Early Child Development Unit Press.

Wiwin Wayan Ni, 2017. Ni Wayan Wiwin Asthiningsih dan Siti Khoiroh Muflihatin. Gambaran Perkembangan Personal Sosial, Adaptif-Motorik Halus, Bahasa, dan Personal Sosial Pada Anak Balita Dengan Metode DDST II Di Posyandu Wilayah Kerja Puskesmas Juanda Samarinda.Volume 5 No. 1 J. Ilmu Kesehat. 5. 